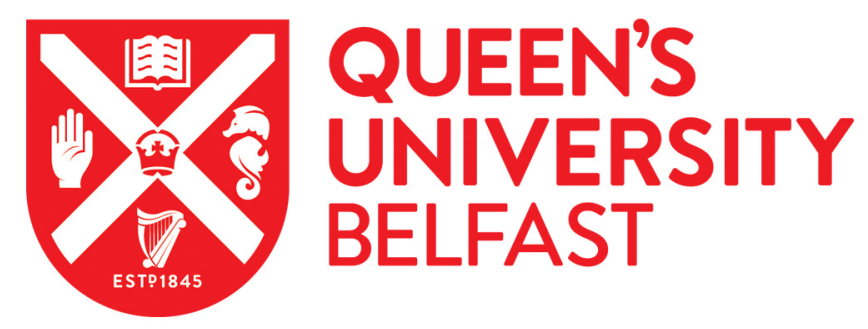

\title{
A multi-perspective exploration of health visitors' family focused practice with mothers who have mental illness and their families: a mixed methods study protocol
}

Leonard, R., Linden, M., \& Grant, A. (2019). A multi-perspective exploration of health visitors' family focused practice with mothers who have mental illness and their families: a mixed methods study protocol. Advances in Mental Health. https://doi.org/10.1080/18387357.2019.1617640

Published in:

Advances in Mental Health

Document Version:

Peer reviewed version

Queen's University Belfast - Research Portal:

Link to publication record in Queen's University Belfast Research Portal

Publisher rights

Copyright 2019, Taylor \& Francis.

This work is made available online in accordance with the publisher's policies. Please refer to any applicable terms of use of the publisher.

\section{General rights}

Copyright for the publications made accessible via the Queen's University Belfast Research Portal is retained by the author(s) and / or other copyright owners and it is a condition of accessing these publications that users recognise and abide by the legal requirements associated with these rights.

Take down policy

The Research Portal is Queen's institutional repository that provides access to Queen's research output. Every effort has been made to ensure that content in the Research Portal does not infringe any person's rights, or applicable UK laws. If you discover content in the

Research Portal that you believe breaches copyright or violates any law, please contact openaccess@qub.ac.uk. 
Journal: Advances in Mental Health.

\section{Title Page}

A multi-perspective exploration of health visitors' family focused practice with mothers who have mental illness and their families: a mixed methods study protocol

1. *Rachel Leonard, $\mathrm{MReS}^{\mathrm{a}}$

rleonard08@qub.ac.uk

2. Dr Mark Linden, $\mathrm{PhD}^{\mathrm{a}}$

3. Dr Anne Grant, $\mathrm{PhD}^{\mathrm{a}}$

*Corresponding author

aSchool of Nursing and Midwifery, Medical Biology Centre, Queen's University, 97 Lisburn Road, Belfast BT9 7BL

\section{Disclosure statement}

The author(s) declare that they have no competing interests. This study is funded as part of RL's PhD stipend, kindly supported by the Department of Education and Learning (DEL).

\section{Authors' contributions}

All three authors contributed to development of ideas and design of the study. RL wrote the first draft of the manuscript, which has been commented on by the other authors. All authors read and approved the final manuscript. 
Journal: Advances in Mental Health.

\begin{abstract}
Background: Maternal mental illness is a major public health issue and can adversely affect the whole family. Worldwide, about $10 \%$ of pregnant women and $13 \%$ of women who have just given birth experience a mental illness, primarily depression and anxiety. Increasingly, research and policy are recognising the benefits of a family focused approach to practice. This approach emphasises the family as the unit of attention. Currently, little research is available which has explored Family Focused Practice (FFP) in health visiting.
\end{abstract}

Objective: This study aims to explore health visitors' FFP with mothers who have mental illness and their partners.

Methods: A mixed-methods sequential explanatory design consisting of two phases; quantitative followed by qualitative, will be utilised in this study. In the first phase, the Family Focused Mental Health Practice Questionnaire will be used to measure the extent of health visitors' family focused practice, and factors that enable and hinder it. The questionnaire will be distributed to practicing health visitors $(n=410)$. In the second phase, semi-structured interviews will be conducted with health visitors, mothers who have mental illnesses and their partners, to further explore and explain the findings from phase one.

Discussion: While the evidence base for the adoption of a family focused approach is growing, there is little understanding of health visitors' family focused practice with mothers who have mental illness and their partners. This study will develop understanding of health visitors' family focused practice, from multiple perspectives, that can be used to inform practice, education, research and policy.

\title{
Keywords
}

Protocol, Mixed Methods, Mental Illness, Family Focused Practice, Health Visiting. 
Journal: Advances in Mental Health.

\section{Background}

Maternal mental illness is a major public health issue (Bauer et al, 2014; Hogg, 2013). Worldwide about $10 \%$ of pregnant women and $13 \%$ of women who have just given birth experience a mental disorder, primarily depression (Stewart et al, 2003). In the United Kingdom (UK) it is estimated that, among parents, $10 \%$ of women have a mental health problem at any given time (Bauer et al, 2014). Whilst parenthood is an important life role, parental responsibilities may affect parents' mental health and recovery (Acri \& Hoagwood, 2015; Foster et al, 2016). Parents with mental illness face multiple challenges, such as, cooccurring substance misuse, physical illness, trauma, and involvement in the criminal justice system (Brandon, Sidebotham, Bailey, \& Belderson, 2010; Nicholson et al, 2001; Social Exclusion Task Force, 2007).

Northern Ireland (a region within the UK) is reported to have a 25\% higher overall prevalence of mental health problems than England (Department of Health Social Services and Public Safety, 2014). Between 10 and 20\% of women develop a mental illness during pregnancy or within the first year after having a baby (Bauer et al, 2014), given that there are approximately 25,000 births per year in Northern Ireland, this suggests that up to 5,000 women could develop perinatal mental illness per year. Despite the high prevalence rates of mental illnesses, $80 \%$ of women in Northern Ireland have no access to specialist perinatal support compared with $40 \%$ in Scotland and England (Bauer et al, 2014).

Parental mental illness may adversely impact children's cognitive, emotional, social, physical and behavioural development on a short or long-term basis (Beardslee, Solantaus, Morgan, Gladstone, \& Kowalenko, 2012; Goodman \& Gotlib, 1999). Twenty-five to fifty percent of children who have a parent with a mental illness will experience some psychological disorder during childhood or adolescence, and ten to fourteen percent of these children will be diagnosed with a psychotic disorder at some point in their lives (Beardslee et al, 2012; van Doesum \& Hosman, 2009). Research also suggests that these adverse impacts are not limited to children (Idstad, Ask, \& Tambs, 2010; Iseselo, Kajula, \& Yahya-Malima, 2016; Ohaeri, 2003). The burden of care on partners and other adult family members has become increasingly recognised in research (Idstad et al, 2010; Ohaeri, 2003). The burden of care on families and partners can put them at increasing risk of psychological, emotional, social, physical and financial problems, it is therefore important to consider the family as a unit in treating mothers with mental illness. 
Families with parents who have mental illness are recognised as a target group for early intervention (Reupert et al, 2013). Increasingly, policy recommends a whole family approach to treatment initiatives (Clarke \& Hughes, 2010; Hughes, 2010). Family focused practice (FFP) is an approach that emphasises the family as a unit in comparison to a narrow focus on the individual (Grant \& Reupert, 2016). Such an approach respects the role of the family, and recognises the impact of parents' mental illness on their parenting, children and other family members (Maybery, Foster, Goodyear, Grant, Tungpunkom, Skogoy, \& Lees, 2015). Family focused practice can promote parents' recovery, and reduce the risk of familial transmission of mental health problems to children (Clarke \& Hughes, 2010; Foster, O’Brien, \& Korhonen, 2012; Hughes, 2010).

International evidence suggests that health care professionals in both adult mental health and children's services experience difficulty in FFP (Grant, Goodyear, Maybery, \& Reupert, 2016; Maybery \& Reupert, 2009; Maybery, Goodyear, O’Hanlon, Cuff, \& Reupert, 2014). In the international context, Australia and the Scandinavian countries have developed system level responses to the increasing evidence and recommendations regarding FFP (Falkov et al, 2015; Goodyear, Hill, Allchin, McCormick, Hine, Cuff and O'Hanlon, 2015). For example, Finland, Sweden and Norway have introduced legally mandated and formalised policies that require mental health care professionals to work with the family members of service users (Lauritzen, Reedtz, Van Doesum, \& Martinussen, 2014). In Australia, there have also been attempts to respond to international policy developments that recommend FFP, through developing multifaceted implementation strategies across organisations to enable the translation of policy into practice (Falkov et al, 2015). Like Australia and the Scandinavian countries, the UK has made concerted efforts to enhance mental health and children's services in response to parental mental illness through policy and practice developments. Statutory and voluntary sector reports (i.e. Think Child, Think Parent, Think Family (Diggins, 2011): Family Minded - Supporting Children who Have a Parent with a Mental Illness (Evans \& Fowler, 2008)) have drawn attention to the needs of parents who have mental illness, and families. In Northern Ireland the Department of Health, Social Services and Public Safety have introduced a range of Think Family initiatives in mental health and children's services. The ultimate goal of Think Family initiatives are to improve outcomes for 
parents who have mental illness, their children and families, by adopting a family focused approach to the planning and delivery of services (Diggins, 2011).

Health visitors within the United Kingdom (UK) are registered nurses or midwives who have undertaken additional postgraduate training in community public health (Peckover, 2011). They work with all families with pre-school children, delivering a universal child health promotion programme, consisting of approximately 9 visits. However, where additional needs are identified, support, frequency of visits, and interventions are tailored to support the family. They are well placed to identify those families requiring additional support, particularly where there is parental mental illness or substance misuse (Cummings \& Whittaker, 2016; Health Education England, 2016; Jenkins, 2015). Health visitors are at the front-line of health care providers during the postnatal period, and play a critical role in identification and early interventions for the improvement of parental and child mental illness (Dumaret \& Picchi, 2005). Recent recommendations for health visitors include early identification and intervention, involvement of a woman's family in her care, and consideration of how mental illness impacts on parenting (National Collaborating Centre for Mental Health, 2014; National Institute for Health and Care Excellence, 2014). Despite these recommendations, a systematic review found that health visitors report a lack of specialised mental health training and insufficient time to adequately address the mental health needs of the family (Ammerman, Putnam, Bosse, Teeters, \& Van Ginkel, 2010).

In addition, there are a number of initiatives within health visiting that incorporate FFP, however these are targeted at specific groups of parents rather than maintaining the universality of health visiting (Ammerman et al., 2005, 2009, 2010; Boris, Larrieu, Zeanah, Steier \& McNeil, 2006). Moreover, current health visiting literature has mostly considered FFP in relation to Post Natal Depression (Belle \& Willis, 2013; Chew-Graham et al., 2008; Chew-Graham, Sharp, Chamberlain, Folkes, \& Turner, 2009; Fletcher, 2009; Rollans, Schmied, Kemp, \& Meade, 2013; Tammentie, Paavilainen, Åstedt-Kurki, \& Tarkka, 2013), with little attention given to other mental illnesses which may be experienced postpartum. However, the majority of research to date has explored FFP in mental health services (Grant \& Reupert, 2016; Maybery, Goodyear, Reupert, \& Grant, 2016; Wong, Wan, \& Ng, 2016), addiction services (Copello, Templeton, Orford, \& Velleman, 2010; Hampson, 2013), and social work (Hughes, 2010; Social Exclusion Task Force, 2007). In addition, little research is available which has explored FFP in health visiting. Given the pivotal role in identifying and treating mental illness, and the introduction of family centred working, understanding how 
Journal: Advances in Mental Health.

health visitors work in a family focused manner is crucial to improve services. This research will determine the predictors of health visitors' FFP and explore FFP from the perspectives of mothers, partners, and health visitors.

\section{Methods/Design}

\section{Aim and objectives}

The aim of the study is to explore multiple perspectives of health visitors' FFP with families impacted by maternal mental illness. The key objectives are:

- To investigate the predictors of health visitors' FFP with families impacted by maternal mental illness;

- To explore the experiences of health visitors regarding their FFP with families impacted by maternal mental illness;

- To explore health visitors' FFP through the experiences of mothers who have a mental illness;

- To explore health visitors' FFP through the experiences of partners of women who have a mental illness;

- To develop recommendations for health visiting practice.

The study will employ a mixed-methods sequential explanatory design consisting of two phases; quantitative followed by qualitative. Following collection of quantitative data (phase 1), the qualitative component will expand upon significant quantitative findings by exploring perspectives of health visitors, mothers and their partners regarding FFP (phase 2). Health visitors for phase 2 will be selected based on high and low scores on the questionnaire from phase 1 . The interpretation of phase 1 data will be guided by the results of phase 2 by providing a context within which the quantitative data can be understood. The use of mixed methods will enable investigation of relationships and trends in quantitative data while also explaining the mechanism behind those trends using qualitative methods (Ivankova, Creswell, \& Stick, 2006; Leech \& Onwuegbuzie, 2010).

\section{Phase one - Questionnaire}

The primary aim of the quantitative phase is to examine the extent and predictors of health visitors' FFP with families impacted by maternal mental illness. Quantitative data will be 
elicited through a questionnaire which includes the Family Focused Mental Health Practice Questionnaire (FFMHPQ) (Maybery, Goodyear, \& Reupert, 2012). The questionnaire pack comprises three sections: demographics; FFMHPQ subscales; and family focused activities. Demographic information collected includes: gender; age; years qualified; training received; employing Healthcare Trust; specialist areas of training; years in post; location of team (i.e. Rural/urban); and current pay band. Section three elicits more in-depth, open-ended questions which aim to capture health visitors' family focused activities. Questions are centred on the contact between health visitor, children, partner and mothers who have a mental illness.

\section{Questionnaire Scale}

Section two of the questionnaire is the FFMHPQ. The FFMHPQ is a tool developed to measure family focused activity, relating to key worker and organisational factors that enable and/or hinder FFP (Maybery et al., 2012). The original measure has 16 subscales which are scored on a seven-point Likert scale (ranging from strongly disagree $=1$, to strongly agree $=$ 7). The 16 subscales are as follows: workplace support; time and workload; policy and procedures; professional development; co-worker support; family and parenting support; worker confidence; assessing the impact on the child; training; skill and knowledge; service availability; connectedness; location issues; engagement issues; support to carers and children and referrals. Five of subscales identified measure family focused activities, while the rest measure organisational factors that can impact these activities. The measure has good content and construct validity and good internal subscale reliability (Maybery et al., 2012), however, due to unsatisfactory reliabilities within the original study, three of the subscales will be removed for the purpose of this study. These include: location issues; engagement issues; and support to carers and children. A low score in a particular subscale suggests a reduced family focus, and a high score increased family focus. A total score was calculated, with the potential minimal score being 41 and the highest being 287 . The scale required minor adaptation; the term 'consumer parent' was changed to 'service user' and the term 'worker' was changed to 'health visitor'. In addition, a factor analysis will be conducted to determine the validity and reliability of the scale within a health visiting population.

\section{Sample characteristics - phase one}

A power calculation was conducted using GPower software (Faul, Erdfelder, Buchner, \& Lang, 2009). At 0.8 power, $p$ value 0.05 , and an effect size of 0.4 , the required sample size is 
Journal: Advances in Mental Health.

80 participants, $10 \%$ was added to this to allow for attrition. This resulted in a final required sample size of 88 health visitors. However, our aim is to use a convenience sampling approach to distribute the questionnaire to the whole population of health visitors in Northern Ireland $(\mathrm{n}=410)$.

Inclusion criteria: Health visitors should have a minimum of 6 months post qualifying experience; Must have direct contact with families; Must be permanent staff (either full time or part time); Possess adequate understanding of the English language to enable completion of the FFMHPQ. Exclusion criteria: Midwifes; Health visitors working within the Nurse Family Partnership team; Health visitors with no contact with families; Agency staff; Managerial level staff; Student health visitors; community psychiatric nurses.

\section{Recruitment of participants- phase one}

Health visitors will be recruited from across the five Northern Ireland Health and Social Care Trusts $(n=410)$. The researcher along with the local collaborator from each Trust will inform potential participants of phase 1 of the study one month prior to commencement via a prenotice letter, which will outline details of the study, and gives participants time to decide if they wish to take part. The local collaborators will be managerial level health visitors. The pre-notice letter will also highlight that the questionnaire is voluntary and that they may choose not to complete the questionnaire, without consequence. The questionnaire will be disseminated through staff meetings in each Trust, which are held approximately once per month. Participants will be given allotted time at the end of the meeting to complete the FFMHPQ. The local collaborator and any other managerial staff will be asked to leave the meeting at this point. Participants will give implied consent through completion of the questionnaire. Health visitors will also be given the option of completing the questionnaire in their own time. If they choose to complete the questionnaire at home they will be provided with a stamped-addressed envelope to return the questionnaire to the research team. This allows for equal opportunities to participate.

\section{Analysis of quantitative data}

Data analysis will be performed using the Statistical Package for the Social Sciences (SPSS) Version 22 for Windows (IBM, 2012). Demographic information collected in Phase one will 
be summarised using descriptive statistics. Descriptive and inferential statistics will be used to measure high and low scores and predictors of FFP. Specifically, hierarchical multiple regression (HMR) will be employed to measure predictors of FFP. HMR was the chosen method of analysis as it can be used to explain or predict a criterion (dependent) variable with a set of predictor (independent) variables (Petrocelli, Cohen, \& Wampold, 2003). HMR allows the investigator to specify a fixed order of entry for variables in order to control for the effects of covariates, and to test the effects of certain predictors, independent of the influence of others (Tabachnick \& Fidell, 2006). Previous studies have found that; available services; skill and knowledge; co-work support (Maybery et al., 2016); own parenting; work setting (Grant et al., 2018a); practitioner experience (Grant et al., 2018a; Goodyear, Maybery, Reupert, Allchin, Fraser, Fernbacher, \& Cuff, 2017); training (Tungpunkom et al., 2017; Goodyear, Maybery, Reupert, Allchin, Fraser, Fernbacher, \& Cuff, 2017); and time and workload (Grant et al. 2018b), were significant predictors of FFP. These predictors will act as variables of interest within the analysis.

\section{Phase two - Participant interviews}

The primary aim of phase two is to expand on the quantitative findings from Phase one, through exploring the experiences of health visitors, mothers and partners.

\section{Health visitor sample}

Follow-up semi-structured, audio recorded, interviews will be conducted with a sub sample of health visitors who completed the FMHPQ and who agreed to participate in interviews. A purposive sampling strategy will be used to identify a sample of approximately 10 participants for interview; this will be determined by data saturation (Glaser \& Strauss, 1967; Morse, 1995). The top 5 highest scoring health visitors and 5 lowest scoring health visitors on the questionnaire, will be identified and invited to participate in semi-structured interviews. A high score indicates an increased family focus, and low score indicates a reduced family focus. With the potential minimal score being 41 and highest being 287. Those with high and low FFMHPQ scores will be selected in order to identify barriers and facilitators to FFP. 
During completion of phase one, participants will be told that their participation in an interview will be contingent upon them returning the completed questionnaire and an accompanying interview volunteer slip. Health visitors selected for interview will be contacted by the researcher and given the opportunity to discuss what is involved in the interview. They will also be made aware of their right to decline participation or withdraw at any point without providing an explanation (Edwards, 2005). If they agree to take part in the interview, a convenient time, date and location will be agreed upon.

Interviews may be held at the health visitors' place of work, or at a quiet, private room within Queen's University Belfast. Written informed consent will be obtained before conducting the interview. Participants will be informed that their data will be held in confidence except in circumstances where they divulge information which may cause harm to themselves, or others, or which might constitute malpractice. A recent systematic literature review (Leonard, Linden, \& Grant, 2018), conducted by the research team, along with phase one quantitative findings will be used to construct topics for the semi-structured interviews. Preliminary topics for interviews include: identification of mental illness; assessment of the family; co-working with other services; family focused activities; and difference in working with perinatal mental illness and serious mental illness. Participants will also be encouraged to discuss topics that they feel are significant and important to them. Interviews will be audio recorded, and transcribed verbatim.

\section{Mothers and partners sample}

Semi-structured interviews will be conducted with a sample of mothers and partners in receipt of health visiting. A purposive sampling strategy will be used, to identify a sample of approximately 20 participants (x10 mothers and x10 partners) also determined by data saturation (Glaser \& Strauss, 1967; Morse, 1995). These participants will be matched against pre-specified inclusion criteria. Participants will be recruited via a local collaborator and one health visitor in each of the five Health and Social Care Trusts in Northern Ireland. These participants will be matched against the inclusion criteria.

Mothers inclusion criteria: Currently be in receipt of health visiting services; Currently have a mental illness which was present before pregnancy, which may coexist with substance misuse; OR have a mental illness that is related to pregnancy or the puerperium period; Currently or previously (in the last 12 months) been involved in mental health services; 
Journal: Advances in Mental Health.

Capacity to give informed consent; Have adequate understanding of the English language. Exclusion criteria: Mothers that have substance misuse problems without the co-existence of a mental illness; Mothers that cannot give informed consent; Mothers enrolled in the Family Nurse Partnership programme; Mothers who do not speak English; Mothers under the age of 18.

Partners' inclusion criteria: Must have a partner experiencing mental illness; Have adequate understanding of the English language. Exclusion criteria: Under the age of 18; Have a diagnosed mental illness; Enrolled in the Family Nurse Partnership programme.

A partner is defined as;

"a person with whom one has a close personal relationship that may be characterised by the partners' emotional connectedness, regular contact, ongoing physical contact and sexual behaviour, identity as a couple, and familiarity and knowledge about each other's lives. The relationship need not involve all of these dimensions” (Breiding, Basile, Smith, Black \& Mahendra, 2015, p.11) .

\section{Recruitment of mothers and partners- phase two}

The researcher and the identified local collaborator will meet with one health visitor in each Trust to present recruitment instructions and eligibility criteria for mothers and partners. This was deemed the most acceptable method of recruitment as the health visitors will be able to identify those who fit the eligibility criteria without the researcher accessing confidential case files. The aim will be to recruit two mothers and two partners from each Health and Social Care Trust. Mothers and partners do not have to be from the same family to be eligible. Mothers do not have to have a partner to be eligible. If a mother is deemed eligible for the study but does not want to take part in an interview, her partner is still eligible to take part and vice versa. Eligible mothers and partners will be recruited in a staggered format, to prevent unnecessary recruitment. Health visitors will be informed that they should pass out two information packs (one for mothers and one for partners) to eligible participants. The information pack will provide a detailed description of what taking part in the study will entail. The researchers contact details will be provided, and potential participants will be informed that they may contact the researcher to discuss what is involved in the interviews, or ask questions, and will be made aware of their right to refuse participation or withdraw (Edwards, 2005). An interview volunteer slip, along with a stamped addressed envelope will 
be included in the information pack. Those who wish take part will return the interview volunteer slip to the researcher, who will then initiate contact.

For those that consent to the interview, a time, date and location will be agreed that suits the participant. All interviews will be conducted separately. Written consent will be obtained before conducting the interview. Participants will be made aware of the strict confidence in which their data will be held, expect in circumstances where they divulge information which may cause harm to themselves or others. The development of the topic guides will be guided by a recent systematic literature review, conducted by the research team, phase one quantitative findings, along with prior consultations with stakeholder groups. Preliminary topics for interviews include: impact of mental illness; involvement of other services; family focused activities; and the needs of the individual family members.

\section{Analysis of qualitative data}

Interviews will be transcribed by the first author, in order to become familiar with the data. Transcriptions of audio recorded interviews will be analysed using thematic network analysis (Attridge-Stirling, 2001). A portion of the transcripts (approx. 25\%) will be checked by another member of the research team to ensure accuracy and improve rigour. Participants will be viewed as the 'experiential expert' (Smith, Flowers, \& Larkin, 2013) while exploring the participants own interpretations of their experiences of FFP. A field diary will be used throughout Phase two to record verbal and non-verbal observations, which will aid data interpretation and analysis (Goodwin \& O’Connor, 2006).

Based on foundations of thematic analysis, defined as, "a method for identifying, analysing and reporting patterns within data."), thematic network analysis offers a web-like network as an organising principle and a representational means (Attridge-Stirling, 2001). The procedures and process that may be employed in going from text to interpretation are made explicit. Attridge-Stirling (2001) describes the process of analysing qualitative data as consisting of three broad stages: the reduction or breakdown of the text; the exploration of the text; and the integration of the exploration (Attridge-Stirling, 2001). While each stage involves interpretation, all involve a more abstract level of analysis. As it is difficult to articulate the difference between these levels of abstraction, Attridge-Stirling (2001) presented six steps which constitute the full process of thematic network analysis: code material; identify themes; construct thematic networks; describe and explore thematic network; and interpret patterns. Zartler (2010) suggests that when analysing multiple 
perspectives in research, consideration must be given to the 'case level' at which data is interpreted. Data will be analysed on a group level, in which interviewees are regarded as distinctive sets of individuals (e.g. Health visitors, mothers, and partners).

In order to assess accuracy of the interpretations, and ensure rigour in the qualitative phase of the research, findings will be discussed and verified by the research team at each stage of the analysis (Lincoln \& Guba, 1985). Techniques such as member-checking, negative case analysis, audit trail, and reflexivity will be employed, as suggested by Lincoln and Guba (1985) to ensure, credibility, transferability, dependability, and confirmability. A further step to ensure robustness and richness of the findings will be through triangulation of phase 1 and phase 2 data. NVivo qualitative data analysis software version 10.0 will be used to assist data management (QSR International, 2012).

\section{Dissemination}

Following completion of the proposed research, the findings will be written up for submission to peer-reviewed journals and conference presentations. Findings will be prepared for health visiting practitioners involved in the study. A lay summary will also be prepared for dissemination to study participants.

\section{Discussion}

While the evidence base of adopting a family focused approach is growing, to our knowledge this study is the first to explore FFP within health visiting. Health visitors play an important role in mother's lives and can identify and support mothers and families in periods of crisis or deterioration of mental health. Data from this study will facilitate our understanding of the extent and predictors of health visitors' FFP and provide information on the factors which help or hinder it. A deeper understanding of these factors can be used to identify areas for improvement within health visiting policy and practice. In addition, the data will also further our understanding of mothers and partners' experiences of health visitors' FFP. Through developing understanding of health visitors FFP we will be able to make recommendations for areas of improvement in the training and education of health visitors, and subsequently improve services for mothers who have mental illness and their families.

\section{Ethical approval}


Journal: Advances in Mental Health.

Ethical approval has been granted by West of Scotland Research Ethics Committee 3 (17/WS/0131) and five NHS Research \& Development offices (17046AG-SP/NT17-0584-08/ SET.17.20/ST1718-10/WT17-09) due to the recruitment of participants from Belfast, Northern, South Eastern, Southern and Western Health and Social Care Trusts.

\section{Disclosure statement}

The author(s) declare that they have no competing interests. This study is funded as part of RL's PhD stipend, kindly supported by the Department of Education and Learning (DEL).

\section{Authors' contributions}

All three authors contributed to development of ideas and design of the study. RL wrote the first draft of the manuscript, which has been commented on by the other authors. All authors read and approved the final manuscript.

\section{Acknowledgements}

The authors wish to thank Dr Helen Kerr and Dr Karen Galway of Queen's University Belfast, and Dr Kerstin Soderstrom of Lillehammer University College for their support and advice throughout the design of this research. We are also thankful to all the individuals who took part in the consultations on the study design and study documentation.

\section{References}

Acri, M. C., \& Hoagwood, K. E. (2015). Addressing Parental Mental Health Within Interventions for Children: A Review. Research on Social Work Practice, 25(4), 395401. https://doi.org/10.1038/nbt.3121.ChIP-nexus

Ammerman RT, Putnam FW, Stevens J, Holleb LJ, Novak AL, Van Ginkel JB. (2005) InHome Cognitive Behavior Therapy for depression: An adapted treatment for first-time mothers in home visitation. Best Practices in Mental Health, 1,1-14.

Ammerman RT, Putnam FW, Altaye M, Chen L, Holleb LJ, Stevens J, et al. (2009) Changes in depressive symptoms in first time mothers in home visitation. Child Abuse \& 
Journal: Advances in Mental Health.

Neglect, 33,127-138.

Ammerman, R., Putnam, F., Bosse, N., Teeters, A., \& Van Ginkel, J. (2010). Maternal

Depression in Home Visitation: a Systematic Review. Aggression and Violent Behavior, 15(3), 191-200. https://doi.org/10.1016/j.avb.2009.12.002.Maternal

Attridge-Stirling, J. (2001). Thematic networks: an analytic tool for qualitative research.

Qualitative Research, 1(3), 385-405. https://doi.org/10.1177/1468794107085301

Bauer, A., Parsonage, M., Knapp, M., Iemmi, V., Adelaja, B., \& Hogg, S. (2014). The costs of perinatal mental health problems. Centre for Mental Health. Retrieved from http://everyonesbusiness.org.uk/wp-content/uploads/2014/12/Embargoed-20th-OctSummary-of-Economic-Report-costs-of-Perinatal-Mental-Health-problems.pdf

Beardslee, W. R., Solantaus, T. S., Morgan, B. S., Gladstone, T. R., \& Kowalenko, N. M. (2012). Preventive interventions for children of parents with depression: international perspectives. The Medical Journal of Australia, 1(Suppl 1), 23-25.

https://doi.org/10.5694/mjao11.11289

Belle, M.-J., \& Willis, K. (2013). Professional practice in contested territory: Child health nurses and maternal sadness. Contemporary Nurse, 43(2), 152-161.

Boris NW, Larrieu JA, Zeanah PD, Steier A, McNeill P. (2006) The process and promise of mental health augmentation of nurse home-visiting programs: Data from the Louisiana nurse-family partnership. Infant Mental Health Journal, 27,26-40.

Brandon, M., Sidebotham, P., Bailey, S., \& Belderson, P. (2010). A study of recommendations arising from serious case reviews 2009-2010. Department for Education.

Braun, V., \& Clarke, V. (2006). Using thematic analysis in psychology. Qualitative 
Journal: Advances in Mental Health.

Research in Psychology, 3(2), 77-101. https://doi.org/10.1191/1478088706qp063oa

Breiding, M., Basile, K., Smith, S., Black, M., \& Mahendra, R. (2015) Intimate Partner Violence Surveillance Uniform Definitions And Recommended Data Elements. Version 2.0. Atlanta (GA): National Center for Injury Prevention and Control, Centers for Disease Control and Prevention.

Chew-Graham, C. A., Sharp, D., Chamberlain, E., Folkes, L., \& Turner, K. M. (2009). Disclosure of symptoms of postnatal depression, the perspectives of health professionals and women: a qualitative study. BMC Family Practice, 10, 7. https://doi.org/10.1186/1471-2296-10-7 [doi]

Chew-Graham, C., Chamberlain, E., Turner, K., Folkes, L., Caulfield, L., \& Sharp, D. (2008). GPs' and health visitors' views on the diagnosis and management of postnatal depression: a qualitative study. The British Journal of General Practice : The Journal of the Royal College of General Practitioners, 58(548), 169-176.

Clarke, H., \& Hughes, N. (2010). Introduction: Family Minded Policy and Whole Family Practice - Developing a Critical Research Framework. Social Policy and Society, 9(04), 527-531. https://doi.org/10.1017/S1474746410000242

Copello, A., Templeton, L., Orford, J., \& Velleman, R. (2010). The 5-Step Method: Principles and practice. Drugs: Education, Prevention and Policy, 17(sup1), 86-99. https://doi.org/10.3109/09687637.2010.515186

Cummings, E., \& Whittaker, K. (2016). Listening visits by health visitors as an intervention for mild-to-moderate postnatal depression or anxiety. Journal of Health Visiting, 4(5), 264-270. https://doi.org/10.12968/johv.2016.4.5.264

Department of Health Social Services and Public Safety. (2014). Making Life Better. A 
Journal: Advances in Mental Health.

whole system strategic framework for public health 2013-2023, (June). Retrieved from https://www.dhsspsni.gov.uk/articles/making-life-better-strategic-framework-publichealth

Diggins, M. (2011). Think Child, Think Parent, Think Family: A Guide to Parental Mental Health and Child Welfare. SCIE, (December 2011), 1-100.

Dumaret, A. C., \& Picchi, V. (2005). Early intervention: psychosocial outcome of families and children's development. Annales Medico-Psychologiques, 163(6), 476-485. https://doi.org/10.1016/j.amp.2004.06.015

Edwards, S. J. L. (2005). Research participation and the right to withdraw. Bioethics, 19(2), 112-130. https://doi.org/10.1111/j.1467-8519.2005.00429.x

Evans, B. J., \& Fowler, R. (2008). Family Minded. Supporting children in families affected by mental illness. Barnardos. Essex. Retrieved from http://www.barnardos.org.uk/family_minded_report.pdf

Falkov, A., Goodyear, M., Hosman, C. M. H., Biebel, K., Skogøy, B. E., Kowalenko, N., ... Re, E. (2015). A systems approach to enhance global efforts to implement family focused mental health ( MH ) interventions. Child and Youth Services, 2298(May 2017). https://doi.org/10.1080/0145935X.2016.1104104

Faul, F., Erdfelder, E., Buchner, A., \& Lang, A. G. (2009). Statistical power analyses using G*Power 3.1: Tests for correlation and regression analyses. Behavior Research Methods, 41(4), 1149-1160. https://doi.org/10.3758/BRM.41.4.1149

Fletcher, R. (2009). Promoting Infant Well-being in the Context of Maternal Depression by Supporting the Father. Infant Mental Health Journal, 30(1), 95-102. https://doi.org/10.1002/imhj.20205 
Journal: Advances in Mental Health.

Foster, K., Maybery, D., Reupert, A., Gladstone, B., Grant, A., Ruud, T., ... Kowalenko, N. (2016). Family-focused practice in mental health care: An integrative review. Child \& Youth Services, 2298(February), 1-27. https://doi.org/10.1080/0145935X.2016.1104048

Foster, K., O’Brien, L., \& Korhonen, T. (2012). Developing resilient children and families when parents have mental illness: A family-focused approach. International Journal of Mental Health Nursing, 21(1), 3-11. https://doi.org/10.1111/j.14470349.2011.00754.x

Glaser, B. G., \& Strauss, A. L. (1967). The Discovery of Grounded Theory: Strategies for Qualitative Research. Observations (Vol. 1). https://doi.org/10.2307/2575405

Goodman, J. H. (2004). Paternal postpartum depression, its relationship to maternal postpartum depression, and implications for family health. Journal of Advanced Nursing, 45(1), 26-35. https://doi.org/2857 [pii]

Goodman, S. H., \& Gotlib, I. H. (1999). Risk for psychopathology in the children of depressed mothers: a developmental model for understanding mechanisms of transmission. Psychological Review, 106(3), 458-90. https://doi.org/10.1037/0033295X.106.3.458

Goodyear, M. , Hill, T. , Allchin, B. , McCormick, F. , Hine, R. , Cuff, R. and O'Hanlon, B. (2015), Family-Focused Practice Standards. International Journal of Mental Health Nursing, 24: 169-180. doi:10.1111/inm.12120

Goodyear, M. , Maybery, D. , Reupert, A. , Allchin, R. , Fraser, C. , Fernbacher, S. and Cuff, R. (2017), Thinking families: A study of the characteristics of the workforce that delivers family-focussed practice. International Journal of Mental Health Nursing, 26: 238-248. doi:10.1111/inm.12293 
Journal: Advances in Mental Health.

Goodwin, J., \& O’Connor, H. (2006). Contextualising the research process: Using interviewer notes in the secondary analysis of qualitative data. The Qualitative Report, 11(2), 374-92. Retrieved from http://nsuworks.nova.edu/cgi/viewcontent.cgi?article=1679\&context=tqr

Grant, A., Goodyear, M., Maybery, D., \& Reupert, A. (2016). Differences Between Irish and Australian Psychiatric Nurses' Family-Focused Practice in Adult Mental Health Services. Archives of Psychiatric Nursing, 30(2), 132-137.

https://doi.org/10.1016/j.apnu.2015.07.005

Grant, A., \& Reupert, A. (2016). The Impact of Organizational Factors and Government Policy on Psychiatric Nurses' Family-Focused Practice With Parents Who Have Mental Illness, Their Dependent Children, and Families in Ireland. Journal of Family Nursing, 22(2), 199-223. https://doi.org/10.1177/1074840716643770

Grant, A., \& Reupert, A. (2016). The Impact of Organizational Factors and Government Policy on Psychiatric Nurses Family-Focused Practice With Parents Who Have Mental Illness, Their Dependent Children, and Families in Ireland. Journal of Family Nursing, 22(2), 199-223. https://doi.org/10.1177/1074840716643770

Grant, A., Reupert, A., Maybery, D., and Goodyear, M. (2018a). Predictors and enablers of mental health nurses' family-focused practice. International Journal of Mental Health Nursing. doi: 10.1111/inm.12503.

Grant, A., Lagdon, S., Devaney, J., Davidson, G., Duffy, J., Perra, O., Galway, K., Leavey, G., and Monds-Watson, A. (2018b). A Study of Health and Social Care Professionals' Family Focused Practice with Parents who have Mental Illness, their Children and Families in Northern Ireland. Summary Report. Belfast: Queen's University Belfast. 
Journal: Advances in Mental Health.

Hampson, C. (2013). Integrating family-focused practice into routine addiction services, (September). Retrieved from http://etheses.bham.ac.uk/3987/

Health Education England. (2016). Specialist Health Visitors in Perinatal \& Infant Mental Health., (March).

Hogg, S. (2013). Prevention in mind. Retrieved from

http://www.nspcc.org.uk/Inform/resourcesforprofessionals/underones/spotlight-mentalhealth_wdf96656.pdf

Hughes, N. (2010). Models and Approaches in Family-Focused Policy and Practice. Social Policy and Society, 9(04), 545-555. https://doi.org/10.1017/S1474746410000266 IBM Corp. (2012). IBM SPSS Statistics for Windows, Version 22.0. Armonk, NY: IBM Corp.

Idstad, M., Ask, H., \& Tambs, K. (2010). Mental disorder and caregiver burden in spouses: the Nord-Trondelag health study. BMC Public Health, 10, 516. https://doi.org/1471-2458-10-516 [pii] $\ln 10.1186 / 1471-2458-10-516$

Iseselo, M. K., Kajula, L., \& Yahya-Malima, K. I. (2016). The psychosocial problems of families caring for relatives with mental illnesses and their coping strategies: a qualitative urban based study in Dar es Salaam, Tanzania. BMC Psychiatry, 16(1), 146. https://doi.org/10.1186/s12888-016-0857-y

Ivankova, N. V., Creswell, J. W., \& Stick, S. L. (2006). Using Mixed-Methods Sequential Explanatory Design: From Theory to Practice. Field Methods, 18(1), 3-20. https://doi.org/10.1177/1525822X05282260

Jenkins, M. (2015). Substance use: The role of the health visitor in supporting families. Journal of Health Visiting, 3(7), 374-380. 
Journal: Advances in Mental Health.

Lauritzen, C., Reedtz, C., Van Doesum, K., \& Martinussen, M. (2014). Factors that may Facilitate or Hinder a Family-Focus in the Treatment of Parents with a Mental Illness. Journal of Child and Family Studies. https://doi.org/10.1007/s10826-013-9895-y

Leech, N. L., \& Onwuegbuzie, A. J. (2010). Guidelines for conducting and reporting mixed research in the field of counseling and beyond. Journal Of Counseling \& Development, 88(1), 61-70. https://doi.org/10.1002/j.1556-6678.2010.tb00151.x

Leonard, R., Linden, M., \& Grant, A. (2018). Family Focused Practice for families impacted by maternal mental illness and substance misuse in home visiting: A qualitative systematic review. Journal of Family Nursing, 24(2), 128-155.

https://doi.org/10.1177/1074840718770612

Lincoln, Y. S., \& Guba, E. G. (1985). Naturalistic Inquiry (1st editio). London: SAGE Publications.

Maybery, D., Foster, K., Goodyear, M., Grant, A., Tungpunkom, P., Skogoy, B. E., \& Lees, R. (2015). How can we make the psychiatric workforce more family focused?, $301-311$.

Maybery, D., Goodyear, M., O’Hanlon, B., Cuff, R., \& Reupert, A. (2014). Profession Differences in Family Focused Practice in the Adult Mental Health System. Family Process, 53(4), 608-617. https://doi.org/10.1111/famp.12082

Maybery, D., Goodyear, M., \& Reupert, A. (2012). The Family-Focused Mental Health Practice Questionnaire. Archives of Psychiatric Nursing, 26(2), 135-144. https://doi.org/10.1016/j.apnu.2011.09.001

Maybery, D., Goodyear, M., Reupert, A. E., \& Grant, A. (2016). Worker, workplace or families: What influences family focused practices in adult mental health? Journal of 
Journal: Advances in Mental Health.

Psychiatric and Mental Health Nursing, 23(3-4), 163-171.

https://doi.org/10.1111/jpm.12294

Maybery, D., \& Reupert, A. (2009). Parental mental illness: A review of barriers and issues for working with families and children. Journal of Psychiatric and Mental Health Nursing, 16(9), 784-791. https://doi.org/10.1111/j.1365-2850.2009.01456.x

Morse, J. M. (1995) 'The Significance of Saturation', Qualitative Health Research, 5(2), pp. 147-149. doi: https://doi.org/10.1177/104973239500500201.

National Collaborating Centre for Mental Health. (2014). Antenatal and Postnatal Mental Health: the Nice Guideline on Clinical Management. The British Psychological Society and The Royal College of Psychiatrists (Updated ed). The British Psychological Society and The Royal College of Psychiatrists. Retrieved from http://www.nice.org.uk/guidance/index.jsp?action=bypublichealth\&PUBLICHEALTH= Mental+health\#/search/?reload

National Institute for Health and Care Excellence. (2014). Antenatal and postnatal mental health: clinical management and service guidance. Clinical guideline [CG192]. https://doi.org/Clinical guideline [CG192]

Nicholson, J., Ph, D., Biebel, K., Hinden, B., Ph, D., Henry, A., \& Sc, D. (2001). Critical Issues for Parents with Mental Illness and their Families.

Ohaeri, J. U. (2003). The burden of caregiving in families with a mental illness: a review of 2002. Current Opinion in Psychiatry, 16(4), 457-465. https://doi.org/10.1097/01.yco.0000079212.36371.c0

Peckover, S. (2011). From 'public health' to 'safeguarding children': British health visiting in policy, practice and research. Children and Society, 27 (2). 
Journal: Advances in Mental Health.

https://doi.org/10.1111/j.1099-0860.2011.00370.x

Petrocelli, J. V, Cohen, B. H., \& Wampold, A. (2003). Problems and Possible Remedies. Measurement and Evaluation in Counseling and Development, 36(April), 9-22.

QSR International. (2012). NVivo qualitative data analysis Software, Version 10. QSR International Pty Ltd.

Reupert, A. E., D, J. M., \& Kowalenko, N. M. (2013). Children whose parents have a mental illness: prevalence, need and treatment. The Medical Journlal of Australia, 199(3 Suppl), S7-9. https://doi.org/10.5694/mjao11.11200

Rollans, M., Schmied, V., Kemp, L., \& Meade, T. (2013). Negotiating policy in practice: child and family health nurses' approach to the process of postnatal psychosocial assessment. Bmc Health Services Research, 13, 133. https://doi.org/10.1186/1472-6963$13-133$

Smith, J. A., Flowers, P., \& Larkin, M. (2013). Interpretative phenomenological analysis.Theory, method and research. London: SAGE Publications Ltd.

Social Exclusion Task Force. (2007). Reaching out: think family. London, UK: Cabinet Office, UK Government. Retrieved from http://webarchive.nationalarchives.gov.uk/20081023153736/http://www.cabinetoffice.go v.uk/social_exclusion_task_force/families_at_risk/reaching_out_summary.aspx

Stewart, D. E., Robertson, E., Phil, M., Dennis, C., Grace, S. L., \& Wallington, T. (2003). Postpartum Depression: Literature review of risk factors and interventions. WHO Publication, (October), 289.

Tabachnick, B. G., \& Fidell, L. S. (2006). Using Multivariate Statistics (5th Edition). Needham Heights, MA, USA: Allyn \&amp; Bacon, Inc. 
Journal: Advances in Mental Health.

Tammentie, T., Paavilainen, E., Åstedt-Kurki, P., \& Tarkka, M.-T. (2013). Public health nurses in Finland help to prevent postnatal depression. Primary Health Care, 23(1), 2631. Retrieved from http://search.ebscohost.com/login.aspx?direct=true \&db=jlh\&AN=108029927\&site=ehost -live

Tungpunkom P, Maybery D, Reupert A, Kowalenko N, Foster K. (2017). Mental health professionals' family-focused practice with families with dependent children: A survey study. BMC Health Services Research. 17(1):1-8.

van Doesum, K. T., \& Hosman, C. M. (2009). Prevention of emotional problems and psychiatric risks in children of parents with a mental illness in the Netherlands: I. Interventions. Advances in Mental Health, 8(3), 264-276. https://doi.org/10.5172/jamh.8.3.264

Wong, O. L., Wan, E. S. F., \& Ng, M. L. T. (2016). Family-centered care in adults' mental health: Challenges in clinical social work practice. Social Work in Mental Health, 2985(October), 1-20. https://doi.org/10.1080/15332985.2015.1038413

World Health Organsiation. (2015). Thinking healthy: A manual for psychosocial management of perinatal depression.

Zartler, U. (2010). Multiple perspectives in qualitative family research: Crafting and conducting research projects. Family Science, 1(3-4), 173-182. https://doi.org/10.1080/19424620.2010.569371 